\title{
Akademisyenlerin Okuryazarlık Algısındaki Değişimler
}

DOI: $10.26466 /$ opus.646592

\author{
Yasemin Uzun* - Gamze Çelik** \\ * Dr.Öğr.Üyesi, Çanakkale Onsekiz Mart Üniversitesi, Eğitim Fakültesi, Çanakkale/Türkiye \\ E-Posta: yaseminuzun@hotmail.com \\ ORCID: 0000-0001-8995-772X \\ ** Arş.Gör.Dr., Çanakkale Onsekiz Mart Üniversitesi, Eğitim Fakültesi, Çanakkale/Türkiye \\ E-Posta: gamzecelik@gmail.com \\ ORCID: $\underline{0000-0003-1683-2349}$
}

\section{Öz}

Okuryazarlık kavramı başlangıçta okuma ve yazma becerisi olarak tanımlanmıştır. Teknolojinin gelişmesi, toplum gereksinimleri ve çoklu ortamın kullanımı ile birlikte kavramın içeriği de değişmiştir. Okuryazarlık genel olarak iyi okuma, yazma, konuşma ve dinleme yeteneği; başkalarıyla etkili iletişim kurabilme ve yazıl bilgileri anlayabilmedir. Yirmi birinci yüzyılda, okuryazarlı kavramı teknoloji kullanımını, problem çözmeyi, işbirliğini ve bilginin sunumunda gerekli olan yetenekleri de içermektedir. Okuryazarlık süreç odaklıdır ve yaşam boyu sürekliliği gerektirir. Bilgi okuryazarlığl, medya okuryazarlığı, dijital okuryazarlık, görsel okuryazarlı, çevre okuryazarlığı, politik okuryazarlık ve kültürel okuryazarlık en sık görülen okuryazarlık türleridir. Bu çalışmanın amacl, akademisyenlerin okuryazarlık algılarındaki değişimi ve okuryazarlık türlerini derslerinde kullanıp kullanmadıklarını tespit etmektir. Bu amaç doğrultusunda Çanakkale Onsekiz Mart Üniversitesi Ĕ̆itim Fakültesi'nde 2018-2019 yılında görev yapan 4 erkek ve 4 kadın akademisyen ile görüşmeler yapılmıştır. Nitel yöntemin kullanıldığı bu çalışmada akademisyenlerin algılarının zaman içinde değiştiği tespit edilmiştir. Akademisyenler okuryazarlık türlerini hem kendi yaşantılarında hem de derslerinde uygulamaktadırlar. Bilgi okuryazarlığı ve görsel okuryazarlık ise derslerde en fazla tercih edilen okuryazarlik türleridir

Anahtar Kelimeler: Okuryazarlık, eğitim, teknoloji, medya, görsel 


\title{
Changes in Academicians' Perception of Literacy
}

\begin{abstract}
The concept of literacy was initially defined as reading and writing skills. The content of the concept has changed with the development of technology, needs of society and the using of multimedia. Literacy is generally being good at reading, writing, speaking and listening; communicating effectively with others and understanding written information. In the twenty-first century, the concept of literacy includes using of technology, problem-solving, collaboration, and the skills necessary to present information. Literacy is process-oriented and requires lifelong continuity. Information literacy, media literacy, digital literacy, visual literacy, environmental literacy, political literacy and cultural literacy are the most common types of literacy. The aim of this study is to determine the changes in the perceptions of academics and whether they use literacy types in their courses. For this purpose, 4 male and 4 female academicians working in Çanakkale Onsekiz Mart University Faculty of Education were interviewed in 2018-2019. In this study, where qualitative method was used, it was found that the perceptions of academicians changed over time. Academics apply literacy types both in their own lives and in their classes. Information literacy and visual literacy are the most preferred types of literacy.
\end{abstract}

Keywords: Literacy, education, technology, media, visual 


\section{Giriş}

Okuryazarlık on dokuzuncu yüzyıla kadar okuma ve yazma becerilerini gerçekleştirmek, yazı sembollerini kullanmak ve bunların anlamlarını çözmek olarak algılanmıştır. Yüzyılın sonlarından itibaren okuma ve yazma becerilerini karşılama anlamına ek olarak belirli bir alanda bilgili ve eğitimli olmayı da gerekli kılmıştır (UNESCO, 2006). Okuryazarlık kavramının zaman içinde kapsamı genişlemiş ve yirminci yüzyılın ortasından itibaren kavramın uygulama alanını ve stratejilerini belirlemeye yoğunlaşılmıştır (Fransman, 2005).

Okuryazarlık genel olarak iyi okuma, yazma, konuşma ve dinleme yeteneği; başkalarıyla etkili iletişim kurabilme ve yazılı bilgileri anlayabilmedir. Nesneleri, olgu ve olayları daha ayrıntılı anlama ve anladıkların kendine özgü ifade etme şekli (Altun, 2005) de okuryazarlık kapsamındadır.

Okuyup yazabilen birey ile okuryazar olan bireyin sahip olması gereken beceriler farklıdır. Okuryazarlık zihinsel becerileri, hesap yapabilme becerisini, teknoloji ile birlikte gelen bilgi ve becerilere sahip olmayı da kapsar (Güneş, 1997).

Çok farklı şekillerde tanımlanan ve yorumlanan okuryazarlık aynı zamanda, karmaşık ve dinamik bir süreci de karşılamaktadır. Toplumun ihtiyaçlarının değişimi, teknolojinin ilerlemesi, kişilerin bilgiye ulaşma şeklinin ve farklı yorumlama becerilerinin gelişmesi de bu durumda etkili olmuştur.

Günümüzde internet ve web ağları aracılığı ile elde edilen sözlü, yazılı, görsel-işitsel iletişim yöntemleri ekran tabanlı (web tabanlı) çok boyutlu hipermetinlere uyarlanmıştır. Bu teknolojiler bağlamında okuryazar olmak, anlamlandırma sürecinde farklı yaklaşımların birbiri ile nasıl birleştirildiğini anlamak demektir (Snyder, 2001). Okuryazarlık bir tür anlamlandırma şeklidir.

Okuryazarlık kavramı uygulamaya dayanan, kazanılmış beceriler toplamı ve öğrenme süreci olarak görülmektedir: Bir dizi beceri olarak okuryazarlık, uygulamalı ve sosyal okuryazarlık, bir öğrenme süreci olarak okuryazarlık ve metin olarak okuryazarlık (Fransman, 2005).

Okuryazarlık süreci yaşam boyu sürekliliği gerektirir. Okuryazar olan kişi, elde ettiği bilgileri yaşamında kullanabilir. Sorunlarının çözümü için bu bilgilerden yararlanır. Okuryazarlık bireyin yaşamını olumlu yönde etkiler 
ve yaşamında gözle görülür bir değişiklik meydana getirir (Yllmaz 1989,s.48).

Bilgi okuryazarlığ okuryazarlık, çevre okuryazarlığı, politik okuryazarlık ve kültürel okuryazarlık en sık görülen okuryazarlık türleridir.

Bilgi okuryazarlığı bilgi ihtiyacını çözmek için çeşitli bilgi kaynaklarına erişme ve bunları kullanma yeteneğini ifade eder. Ancak, insanların değişen bir teknolojik ortamda bireyler ve gruplar arasındaki fikir akışını ifade etmelerine, keşfetmelerine, sorgulamalarına, iletişim kurmalarına ve anlamalarına olanak tanıyan karmaşık bir dizi becerinin geliştirilmesi olarak da tanımlanabilir.

Bilgi okuryazarı, problemlere bilgiye dayalı çözüm üretmek için bilgi kaynaklarını kullanır, çeşitli bilgi kaynaklarının kullanımı için gerekli becerilere sahiptir ve ilgili teknikleri bilir (Kurbanoğlu, 2010, s.725).

Medya okuryazarlı̆̆ı, medya üzerinden sunulan tüm materyallerin hazırlanış süreçlerini ve materyalleri eleştirel bir gözle okuma, topladığı bilgileri alternatif format ve ortamda sunma ve yayınlama becerilerini (Aytaş, 2017, s.297) kapsar. Bu tür okuryazarlık çeşitli ortamların bilgisine ve kullanımına atıfta bulunabilir. Ayrıca eleştirel sorgulama becerilerini de gerektirir.

Bilgisayar okuryazarlı̆̆ genellikle bilgisayar dili ile ilgili çeşitli görevleri yerine getirmek için gereken yeterlilikleri ifade eder. Zamanla bu terim dijital okuryazarlık olarak değiştirilmiştir: İş, eğlence ve iletişim için elektronik medyanın kullanılması. Bu yeterlilikler mantıklı ve eleştirel düşünme, üst düzey bilgi yönetimi becerileri ve iyi gelişmiş iletişim becerileri ile ilgilidir. Bilgisayar ortaminda sunulan farklı formlardaki bilgiyi anlama becerisi olarak da tanımlanan dijital okuryazarlık dijital medyanın kullanımıdır (Ocak, Karakuş, 2018, s.1429).

Görsel mesajları anlamlandırma ve mesaj oluşturma gücü olarak tanımlanan (Alpan, 2008, s.76) görsel okuryazarlık, teorik bakış açılarını, görsel dil bakış açılarını, sunum bakış açılarını ve sayısal olarak ifade etme dahil teknolojik gelişmeleri içeren disiplinlerarası bir kavram olarak kullanılmaktadır. Uluslararası Görsel Okuryazarlık Derneği (IVLA) görsel okuryazarlığın şunları içerdiğini ileri sürer (Pettersson, 1993):

- Bir insanın görerek ve aynı zamanda başka duyularını da kullanarak içeriği bütünleştirerek geliştirebileceği bir grup yetkinlik, 
- Görsel sembollerin (görüntülerin) iletişimini yorumlayabilme ve görsel semboller kullanarak mesajlar oluşturabilme,

- Görsel görüntüleri sözlü dile veya bunun tam tersine çevirme yeteneği,

- Görsel medyada görsel bilgiyi arama ve değerlendirme yeteneği.

Her ne kadar çevresel okuryazarlık fikri, geleneksel okuryazarlık kavramından ayrı gibi görünse de okuryazarlığın metin temelli olmayan bir bağlam olarak en eski kullanıldığı alanlarından biridir. Çevresel okuryazarlık, temel olarak, çevresel sistemleri algılayıp yorumlama ve bu sistemleri koruma, iyileştirme veya iyileştirmek için uygun önlemleri alma becerisidir. Çevre okuryazarı bir bireyin doğa ve doğa olaylarına yönelik eleştirel düşünceler üretebilen, bu doğrultuda araştırma ve sorgulama yapabilen bir bireydir (Fettahlığlu, 2018, s.405).

Politik okuryazarlık veya sivil okuryazarlık, politikadaki vatandaşları anlamak, kullanmak ve onlarla bağ kurmak için gereken becerileri kapsar. Politik okuryazarlık, özellikle ulusal düzeyde, vatandaşlık haklarına ilişkin bilgi ve bunlara erişim anlamına gelir, bilgi kadar beceriyi de gerektirir (Kuş, 2013, s.208).

Kültürel okuryazarlık yüksek kültür olarak tanımlanan edebiyat ve sanat gibi alanlara erişimi ifade eden yeni bir kavramdır (Fransman, 2005, s.9-10).

Okuryazarlık türleri, özellikle görsel okuryazarlık üzerine, çok fazla çalışma yapılmıştır (Tanrıverdi ve Apak, 2013). Ancak akadermisyenlerin derslerinde hangi okuryazarlık türlerini tercih ettiğine dair bir çalışmaya rastlanmamıştır.

$\mathrm{Bu}$ çalışmanın amacı üniversitede görev yapan akademisyenlerin okuryazarlık algılarını ve derslerinde hangi okuryazarlık türlerini kullandıklarını belirlemek; en çok kullanılan okuryazarlık türleri ile ilgili eğilimleri ortaya çıkarmak, okuryazarlık alanında gelecekte yapılacak olan çalışmalar için neye gereksinim duyulduğunu belirlemede yol gösterici olmak ve ve okuryazarlık türlerinin kullanımının yaygınlaşmasına katkı sağlamaktır. Bu çalışmanın alanyazındaki bu eksiliğin giderilmesine katkı sağlayacağı düşünülmektedir. 


\section{Yöntem}

Nitel araştırma yöntemlerinin kullanıldığı bu araştırmada, araştırma deseni örnek olay (durum çalışması), veri toplama aracı olarak yarı yapılandırılmış görüşme formu kullanılmıştır.

Akademisyenlere aşağıdaki sorular yöneltilmiştir:

1. Gelişen teknolojiyle birlikte okuryazarlık algınızda nasıl bir değişim olduğunu gözlemlediniz?

2. Derslerinizde görsel okuryazarlıkla ilgili herhangi bir çalışma yapıyor musunuz?

3. Facebook, twitter, akademia.edu, researchgate ya da herhangi bir sosyal ağ kullanıyor musunuz? Neden?

4. Okumayı sevmeyen birisi, dergi okuyor, internetteki sosyal ağlardan yazılar, şiirler okuyorsa, bu kişi size göre gerçekten okumayan bir birey midir?

5. Derslerinizde en çok hangi okuryazarlık türünü kullanıyorsunuz? Neden?

6. Bilgi okuryazarı olan bir birey, bilgiye nasıl ulaşacağı konusunda kendisini geliştirmiştir. Bireyin topluma aktif olarak katılması için gereken zorunlu becerilerin bütünü olarak tanımlanan bilgi okuryazarlığı size ne ifade etmektedir?

7. Sizce bilgi okuryazarı olan bir birey topluma aktif olarak nasıl katılabilir?

8. Size göre bölümünüzde alan dersleri dışında görsel okuryazarlık, medya okuryazarlığ ya da bilgi okuryazarlığı dersi verilmeli midir?

Görüşme; insanlarda doğrudan gözlemleyemediğimiz şeyleri tespit etmek için kullanılan bir veri toplama aracıdır. İnsan karşıdan baktığında bir insanın bakış açısını anlayamaz. Görüşmelerin amacı; diğer insanların bakış açılarını ortaya koyabilmektir. Nitel görüşmelerle, katılımcılar dünya görüşlerini açıklama şansını yakalar. Düşüncelerini daha özgür bir şekilde ifade edebilir (Patton, 2014).

Yapılan görüşmeler, görüşme formu kullanılarak tamamlanmıştır. Bazı katılımcılarla ise araştırmacılar görüşmeyi yapmış ve katılımcıların söylediklerini not almışlardır. Araştırmacılar görüşmelerde ortaya çıkan 
düşüncelerden kodlar belirlemiştir. Bu kodların güvenirliğini belirlemek için başka bir araştırmacıdan yardım alınmıştır. Her iki araştırmacı tarafindan elde dilen bulgular, Miles ve Huberman (1994, s.64)'1n ortaya koyduğu güvenirlik formülüyle karşılaştırılarak hesaplanmıştır:

Güvenirlik = Görüş Birliği / (Görüş Birliği + Görüş Ayrılığı) = 123/ $(123+6)=0,95$. Yapılan çözümlemeler sonucunda, araştırmanın güvenirliği 95 olarak bulunmuştur. Miles ve Huberman (1994)'e göre bir araştırmanın güvenilir sayılabilmesi için kodlama güvenirliğinin en az .80uyum seviyesinde olması gerekmektedir (akt; Creswell, 2013).

\section{Katılımcilar}

Tablo 1. Katılimcilar

\begin{tabular}{llll}
\hline Katılımc1 & Cinsiyet & Yaş & Bölüm \\
\hline $1 \mathrm{~K}$ & Kadın & $30-35$ & Fizik Eğitimi \\
\hline $2 \mathrm{~K}$ & Kadın & $45-50$ & PDR \\
\hline 3E & Erkek & $35-40$ & Kimya Ĕ̆itimi \\
\hline $4 \mathrm{E}$ & Erkek & $30-35$ & Coğrafya Eğitimi \\
\hline $5 \mathrm{~K}$ & Kadın & $35-40$ & Sınıf Eğitimi \\
\hline $6 \mathrm{E}$ & Erkek & $30-35$ & Tarih Eğitimi \\
\hline $7 \mathrm{E}$ & Erkek & $25-30$ & Türkçe Ĕ̆itimi \\
\hline $8 \mathrm{~K}$ & Kadın & $45-50$ & Eğitim Yönetimi \\
\hline
\end{tabular}

Araştırmaya katılan akademisyenler Çanakkale Onsekiz Mart Üniversitesi'nde görev yapmakta olan 8 kişiden oluşmaktadır. Katılımcıların 4'ü erkektir, 4 katılımcı ise kadındır. Örneklem random yoluyla seçilmiştir. Fizik eğitimi, PDR, kimya eğitimi, coğrafya eğitimi, sınıf eğitimi, tarih eğitimi, Türkçe eğitimi, eğitim yönetimi gibi farklı alanlardan hocalarla birebir görüşme yapılmıştır. Katılımcılar 25-50 yaş aralığındadır.

\section{Bulgular}

Yapılan görüşmeler sonucu okuryazarlık türlerine göre elde edilen bulgular sırasıyla şu şekilde verilmiştir: 
Tablo 2. Okuryazarlık Algısındaki Değişim

\begin{tabular}{ll}
\hline Tanımlayamıyorum & $1 \mathrm{~K}, 2 \mathrm{~K}, 3 \mathrm{E}$ \\
\hline Değişmedi & $5 \mathrm{~K}, 6 \mathrm{E}, 7 \mathrm{E}$ \\
\hline Değişti & $4 \mathrm{E}, 8 \mathrm{~K}$ \\
\hline Teknolojinin kolaylaştıııcılı̆̆ı & $6 \mathrm{E}, 1 \mathrm{~K}, 2 \mathrm{~K}, 3 \mathrm{E}$ \\
\hline Sosyal medyanın etkisi & $4 \mathrm{E}, 2 \mathrm{~K}$ \\
\hline Derslerde kullanılmasının yaygınlaşması & $8 \mathrm{~K}$ \\
\hline E kitapları okumada artış & $6 \mathrm{E}, 5 \mathrm{~K}$ \\
\hline
\end{tabular}

Katılımclara sorulan "Gelişen teknolojiyle birlikte okuryazarlık alg1nızda nasıl bir değişim olduğunu gözlemlediniz?" sorusuna yönelik cevaplar incelendiğinde 3 katılımcı okuryazarlık algısındaki değişimi tanımlayamadığını belirtmiştir. 3 katılımcı okuryazarlık algısının değiştiğini düşünürken, 2 katılımcı okuryazarlık algısında herhangi bir değişim olmadığını ifade etmiştir. Bu algı değişikliğinde sosyal medyanın etkisinin olduğunu düşünen 2 katılımcı vardır. 1 katılımcı bu duruma derslerde kullanılmasının yaygınlaşmasının etkisi olduğu görüşündedir. 2 katılımcı ise elektronik kitap okumadaki artışın etkisi olduğunu düşünmektedir.

- “Teknolojik okuryazarlik, bilimsel okuryazarlı̆̆a girersem, teknolojiyle beraber bilimsel bilgi çok rahat insanlara ulaşıyor. Aynı şekilde kendim için de çok rahat bilimsel bilgiye ulaşıyorum. Hayır, hissetmiyorum. Kendim için hissetmiyorum. O farkı nasıl hissedeceğimi bilmediğim için. Meslek hayatıma bilgisayarla başladım. Yirmili yaşlarımın başlarından beri teknoloji bana hizmet ediyor. Gelişen teknolojinin en büyük etkisi benim için bilgiye kolay ulaşmak. Ama bu hangi okuryazarlık becerimi etkiliyor. Onu bilmiyorum." (1K)

- "Mutlaka olmuştur ama tam olarak açıklayamıyorum. Biraz kafa yorulması gereken bir konu. Nasıl değişim oldu? Kendi alanımla ilgili kaynaklara ulaşabiliyorum. Önceden böyle bir kolaylık yoktu. İnternetten veri tabanlarını kullanıyorum. Dergilere ulaşabiliyorum. Çalıştığım alanla ilgili kaynaklar okuyabiliyorum. Okuma kolaylı̆̆ı sağlıyor. Öyle bir kolaylı̆̆ı oldu. Ben de daha çok o anlamda kullanıyorum. Sosyal ağlar yerine daha çok veri tabanları. Illetişim açısından mail kullanıyorum." (1K) 
- "Bu konuda aşırı bilgi sahibi değilim. Okuryazarlık dediğimiz şey, ilgilendiğimiz alanı en doğru şekilde anlayabilmek şeklinde düşünüyorum. Teknolojinin gelişmesiyle birlikte, bilgisayar teknolojisi, farklı araçları hayatımızın içine soktu. O konuyla ilgili temel kavramları da bilmek önemli." (3E)

- "Yeni teknolojilerle birlikte insanlarm okuryazarlı̆̆ tembelleştiriliyor, çünkü sosyal ağlar insanlarm bilginin özüne ulaşmasını engelliyor. Kendilerine sunulanla yetinmiyorlar. Özellikle 14-19 yaş grubunda kitap okumaktansa sosyal ağları okumak yayginlaşıyor. Kitap okumanın vakit kaybı olduğu öğretiliyor. Yeni teknolojilerle birlikte bireylerin okuryazarlı̆̆ı kavramı da onları tembelleştiriyor. Çünkü onlara sunulan gerek facebook, twitter insanlarm bilginin özüne ulaşmasına değil, verilen neyse ona ulaşmasını sağhlyor. İnsanlar onu algılıyor. Özellikle erişkinliğe geçen bireylerde (9-8 yaş) kitap okumaktansa sosyal ă̆ları okumayı tercih ediyor. Kitap okumanın vakit kaybı olduğu öğretiliyor." (4E)

- "Okuryazarlik kavraminn eskiden beri var olan haliyle değişmediğini düşünüyorum. Okuryazar olan kişi, ilgilendiği konuyla ilgili araştıran, ilgili kişiydi. Bu şimdi de böyle. Okuryazarlık kavramı temelde değişmedi, sadece biçimi değişti. Bu demek değil ki medyadan okuyan herkes okuryazar. Kendi değerleri dışında eleştirel bakış açısıyla değgrlendiremezse yine okuryazar olmuş olmuyor." (5K)

- “Kindle ortaya çıktı. Çeşitli okuma şeyleri, bu e-reader'lar ortaya çıktı. Çözünürlük oranı yüksek şeyler çıktı. Çok fazla e-kitap oldu. Bunlar okuryazarlı̆̆ı hızlandırdı. Fakat okurken öğrenme açısından paper (kâğıt) bazlı sistem olsun, kitaplar, okurken ben halâ onlarn tercih etmeye çalışıyorum. Neden? Çünkü Ingiltere'de yaptılar bu araştırmayı. Not alıyorsun. Kalem kullanarak okuma yapmak yaratıcilı̆̆ arttıriyor. Bu ortaya çıkarılmış." (6E)

- “Okuryazarlik diyoruz ama neye göre okuryazarlik? Okuma yazma orada kasıt? Yoksa farklı amaçlar için mi? Medya okuryazarlığı deyince tabletleri mi kapsıyor, telefonları mı kapsıyor? Bunlarla ne kadar bilgi edinilebilir? Orası muamma. Ama daha doğrusu okuryazarlık nedir? Onun bir tanımı 
yapılması gerekir? Bütün elektronik şeyler medya okuryazarlı̆̆ı mı? Görsel okuryazarlıkla medya okuryazarlı̆̆ı arasında ne fark var? Ben açıkçası bilgisayar üzerinden okuyamıyorum. Ĕ̆er 30-20 sayfaysa çıktı alıyorum. Telefondan da kısa okuyorum. Çünkü sıkıllyorum. Aynı metni kâğıt üzerinden okusam sıkılmam." (7E)

- "Bilişim yeni bilgi okuryazarlığı, internet okuryazarlığı, bu kavramlar birbirinin alternatifi. Derslerimizde en çok kullandığımız bilgi okuryazarlı̆̆ı, internet okuryazarlı̆̆ı. Medya okuryazarlı̆̆ da kullanıyoruz. Seçici olmaları, farkında olmaları, topluma önder bireyler yetiştirmeye çalışıyoruz. Bunlarn öğretmen adayları tarafindan fark edilebilmesi için açıklayıcı ifadeler kullanıyor. Üniversite sadece eğitim öğretim değil, araştırma için olmasindan bilgi okuryazarlı̆̆ı, internet okuryazarlı̆̆ı gerektiriyor. Öğrencilerimizin bu tür becerilerini geliştirmeye çalışıyoruz."

Tablo 3. Derslerde Görsel Okuryazarlık Çalışmaları

\begin{tabular}{ll}
\hline Evet & $2 \mathrm{~K}, 4 \mathrm{E}, 5 \mathrm{~K}, 7 \mathrm{E}, 8 \mathrm{~K}$ \\
\hline Kısmen & $3 \mathrm{E}, 6 \mathrm{E}$ \\
\hline Hayır & $1 \mathrm{~K}$ \\
\hline Okur olma bilinci verilmesi & $8 \mathrm{~K}$ \\
\hline Etik olmadı̆̆ını düşünme & $2 \mathrm{~K}$ \\
\hline
\end{tabular}

Derslerde görsel okuryazarlıkla ilgili 5 akademisyen çalışma yaptığını belirtmiştir. 2 akademisyen kısmen çalışma yapabildiğini belirtmiştir. 1 akademisyen çalışma yapmadığını ifade etmiştir. 1 katılımcı öğrencilere okur olma bilincinin kazandırılması gerektiğine dikkat çekmiştir. Başka bir katılımcı ise bu şekilde yapılan çalışmaların etik değer taşımadığı görüşündedir.

- "Görsellerden yararlaniyorum ama çok istediğim düzeyde değil. Görseller kısmından. Veri kaynaklarından arıyorum. Uygun olanları seçiyorum: Bunların etik olmadığın düşünüuorum.Başkasının resmi, karikatürü. Kendim yapmadığıma göre. Siteden karikatür alıp uygun bir şeyse kullanıyorum. Mizah da dersin içinde olmalı diye düşünüyorum. Daha önce bunlara ulaşabilmemiz mümkün değildi. Şimdi daha çok. Daha ulaşabiliyoruz, bulabiliyoruz. Önceden bulamayacağım için düşünmüyordum, kullanmıyordum. Şimdi internet elimizin altında. Birçok konuda materyal bulabiliyor insan."(2K) 
- “Hayır. Dersimde görsel materyaller kullanıyorum. Öğrencilerin görsel okuryazarlı becerileri üzerinde bir çalışma yapmadım. Ama bol bol kullan-yorum. Yeri geldikçe kullanıyorum. Bütün öğretim üyeleri sunum kullanyor. Bu da görsel bir materyal sonuçta." (3E)

- "Bölüm gereği görsel anlamlandırmanin daha değerli olduğuna inaniyorum. Bölüm hocalarmmn 70'lerden kalma kitaplarla ders anlatımmm nasıl eleştirdiysek bugün lise ve ortaokul öğretiminde daha iyi bilgi sunmak için yeni yayınları takip etmeliyiz. Bilgi bir güçtür ama teknolojiyi nasıl kullandığımız önemlidir. Örneğin evdeki uydu yayınlarını, normal kanalları hd izleyebilirsin yada daha bilgilendirici kanallarn seçebilirsin. Ülkemizde ne yazık ki dizilerle birlikte insanlarm algısı ve bakış açısı değiştiriliyor. Diziler daha yaygin olduğu için örnek verdim. Teknolojinin nasıl kullanıldığı, sosyal medya açısından da önemlidir." (4E)

- IIlk okuma yazma öğretimi dersine girdiğimiz için, görsel okuma ve görsel sunu becerilerden biri. Görsel okuma, görsel sunu nasıl yaptırllir? Ders materyallerindeki görselleri yansitarak bunlar nasıl uygulanmalı? Görseli yansıtıp, üzerinde tartışıyoruz. Öğrencilerin yorumlama yapması gereken becerileri içeriyor mu? Konu zaten dersimin içeriğinde. Diğer derslerimde de dikkat çekme amacıyla konuyla ilgilenmelerini sağlamak için, görsellerden yararlanıyorum. Bu kısa videolar da olabiliyor. Karikatür de olabiliyor." $(5 \mathrm{~K})$

- "Görselleri kullanarak harita ya da bir gravür, ya da o dönemden kalma bir painting. Budur yani. Bunun dışında bir görsel okuma, bu malzemeler. Çok büyük görsel malzeme kullanmam, ulaşamam. Tarih alanı soyut bir alan." (6E)

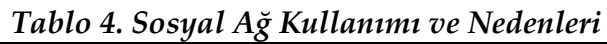

\begin{tabular}{ll}
\hline Kullaniyorum & \\
\hline Facebook & $1 \mathrm{~K}, 3 \mathrm{E}, 4 \mathrm{E}, 5 \mathrm{~K}, 6 \mathrm{E}, 7 \mathrm{E}$ \\
\hline Twitter & $1 \mathrm{~K}, 3 \mathrm{E}, 6 \mathrm{E}, 7 \mathrm{E}$ \\
\hline Diğerleri (instagram, pinterest vb. ) & $1 \mathrm{~K}, 3 \mathrm{E}, 4 \mathrm{E}, 5 \mathrm{~K}, 6 \mathrm{E}$ \\
\hline
\end{tabular}


Tablo 4'te sosyal ağları katılımcıların çoğunluğunun kullandığı görülmektedir. En yoğun olarak facebookta zaman geçirildiğini görmekteyiz. Bununla birlikte Pinterest de ilgi duyulan diğer bir sosyal ağdır.

- "Kullanmiyorum. Bilmiyorum. Yüz yüze görüşmeyi tercih ediyorum. Insanlar çok samimi gelmiyor bana. Insanlarm her şeyini ortaya koymaları bana hoş gelmiyor. Ben de öyle bir şey istemiyorum. O sitelere baktığımda bunu görüyorum. Bireylerin yaptı̆̆ çalışmaları görmesi açısından gerekli akademia.edu aslinda. Facebook ilişkiler bitiyor. Researchgate yabancılar var, dili çok iyi kullanmak gerek. Diğer türlü bir anlamı yok. Yapılmış olanın çalışılmaması açısından iyi. Bir dergide yayınlıyorsunuz. O dergiden izinsiz alınması pek etik değil. Araştırma için birisini bulabilirsiniz. Dil konusunda kendimi iyi hissetmediğim için çok etkili kullanmiyorum. Üyeyim oraya. Etik sorunlar var. Bu konuda insanlar aydınlatılmah. Ayruca researchgate gibi siteler faydalı da önerebilirim." $(2 \mathrm{~K})$

Tablo 5. Kullanma Nedenleri

\begin{tabular}{lll}
\hline Kullanma Nedenleri & & \\
\hline Facebook & $\bullet$ & Eğlence amaçlı olması (5K) \\
& $\bullet$ & Arkadaşlarla iletişim $(1 \mathrm{~K}, 3 \mathrm{E}, 4 \mathrm{E}, 6 \mathrm{E})$ \\
& $\bullet$ & Ulaşılamayan arkadaşlara ulaşma (3E) \\
\hline Twitter & $\bullet$ & Bilgi alma (1K, 3E) \\
& $\bullet$ & Haberleri takip etme (6E, 7E) \\
\hline Pinterest & $\bullet$ & Bilgi almak (1K, 5K) \\
& $\bullet$ & Ilgi alanına yönelik olması (1K) \\
\hline
\end{tabular}

Tablo 5'te kullanma nedenleri arasında, Facebook'un özellikle arkadaşlarla iletişim kurmaya yardımc olmasının büyük etkisi olduğu görülmektedir. Ayrıca katılımcllar Twitter'ı bilgi alma ve haberleri takip etmede kullandıklarını belirtmişlerdir. Ayrıca Pinterest'i de ilgiyle takip eden katılımcilar vardır.

- "Bir kere ilgi alanlarna yönelik websitelerine, bloglarma ulaşmamı sağhlyor. Dünyanm birçok yerindeki insanlar ilgi alanına göre paylaşım yaptığında sana geliyor paylaşımlar. İstediğin bilgiye en kısa yoldan ulaşmanı sağhlyor." (1K) 
- "Facebook kullanıyorum. Bazı açılardan yararlı, bazı açılardan zararlı. Yurtdışına gittiğgimde açtım. Daha öncesinde yoktu. Akademia.edu kullanıyorum. Google plus var, otomatik. Facebook çok zaman alıyor. İnsanlarm paylaştı̆̆ ş̧eylere bakma isteği doğuyor. Bu düşünceye halâ inanıyorum. Ulaşamadığım, eskiden beri ulaşamadığım insanlara ulaşmamı kolaylaştırnyor. Insanlar bilgilendirme adına kullamlabilecek bir araç. Örnek verecek olursak, günümüzde atmosferle, çevre sorunlarıyla ilgili bilgi sahibi değiliz. Facebooktan video paylaşıp, bu konuda bilgi sahibi olabilirler."(3E)

Tablo 6. Kullanmama Nedenleri

\begin{tabular}{ll}
\hline Kullanma Nedenleri & \\
\hline Facebook & İnsanların samimi olmaması (2K) \\
& Özel hayatın gizliliğini koruma isteği (2K,8K) \\
\hline Researchgate & Yabanc dil yetersizliği (2K) \\
& Etik sorunlar (2K) \\
\hline
\end{tabular}

Sosyal medya hesaplarını donduran veya hiç açmamayı tercih eden katılımcılar da bulunmaktadır. Facebook'u insanların samimi olmamaları ve özel hayatın gizli kalması gerektiği düşünceleriyle kullanmayanlar olduğu görülmektedir.Researchgate ise pek çok katılımcı için bilimsel araştırmaların paylaşılması yönüyle faydalıdır. Ancak bazı katılımcılar, yabancı dilin burada sorun ortaya çıardığını belirtmişlerdir. Ayrıca etik sorunların da ortaya çıkabileceğini düşünen katılımcılar da bulunmaktadır.

- “Bilmiyorum. Yüzyüze görüşmeyi tercih ediyorum. İnsanlar çok samimi gelmiyor bana. Insanlarn her şeyini ortaya koymalar bana hoş gelmiyor. Ben de öyle bir şey istemiyorum. O sitelere baktığımda bunu görüyorum. Bireylerin yaptığ çalışmaları görmesi açısından gerekli akademia.edu aslında. Facebook ilişkiler bitiyor. Researchgate yabancilar var, dili çok iyi kullanmak gerek. Diğer türlü bir anlamı yok. Yapılmış olanın çalı̧ıılmaması açısından iyi. Bir dergide yayınltyorsunuz. O dergiden izinsiz alınması pek etik değil. Araştırma için birisini bulablirsiniz. Dil konusunda kendimi iyi hissetmediğim için çok etkili kullanmiyorum. Üyeyim oraya. Etik sorunlar var. Bu konuda insanlar aydınlatılmal. Aynca researchgate gibi siteler faydah da önerebilirim." (2K)

- “Facebook kullaniyordum. Sonra kullanmamaya başladım. Researhgate'e kayıtlıyım. Facebook hesabımı özel yaşantımı ön plana çıkarıyor diye don- 
durdum ve tehlikeli. Tez indirmek için girmek durumunda kalıyoruz. Özel hayatın çok açıklanması taraftarı değilim. Paylaşılmasında da sınır olması gerektiğini düşünüyorum. Sürekli girip oradaki bilgileri güncellemek. Ulaşmak istedikten sonra arkadaşlarıma kolaylkkla ulaşabiliyorum.Zamanimizin olmaması da bir etken." (8K)

Tablo 7. Dijital Okuma

\begin{tabular}{ll}
\hline Okuyan katılımc1 & $1 \mathrm{~K}, 2 \mathrm{~K}$ \\
\hline Okumayan katılımc1 & $4 \mathrm{E}, 6 \mathrm{E}, 7 \mathrm{E}$ \\
\hline Kısmî okuryazar & $3 \mathrm{E}, 5 \mathrm{~K}, 8 \mathrm{~K}$ \\
\hline
\end{tabular}

Dijital okumayı tercih eden iki kişi bulunmaktadır. Üç katılımcı basılı kitaplardan okumayı tercih etmektedir. Diğerleri ise hem dijital kitapları hem basılı kitapları okumaktadır.

- "O farkı nasıl hissedeceğimi bilmediğim için. Meslek hayatıma bilgisayarla başladım. Yirmili yaşlarımın başlarından beri teknoloji bana hizmet ediyor. Gelişen teknolojinin en büyük etkisi benim için bilgiye kolay ulaşmak." (1K)

Tablo 8. Kullanılan Okuryazarlık Türü

\begin{tabular}{ll}
\hline Bilgi okuryazarlığı (Bilimsel okuryazarlık) & $1 \mathrm{~K}, 5 \mathrm{~K}, 7 \mathrm{E}, 8 \mathrm{~K}$ \\
\hline Görsel okuryazarlık & $2 \mathrm{~K}, 3 \mathrm{E}, 8 \mathrm{~K}$ \\
\hline Medya okuryazarlı̆̆1 & $5 \mathrm{~K}, 8 \mathrm{~K}$ \\
\hline Teknoloji okuryazarlığı & $5 \mathrm{~K}$ \\
\hline Geleneksel okuryazarlık (Kitap okuma) & $6 \mathrm{E}$ \\
\hline
\end{tabular}

Tablo 8'e bakıldığında araştırmamıza katılan akademisyenlerin derslerinde en çok bilgi okuryazarlığını ve görsel okuryazarlığı kullandıklarını görmekteyiz. Medya okuryazarllğıı, teknoloji okuryazarllğı ve geleneksel okuryazarlık ise daha az yararlanılan okuryazarlıklardandır. Bu durum görsellerin derse ilgiyi arttırmasına katkı sağlamasından kaynaklanmıştır şeklinde yorum yapılabilir. Ayrıca bilgi okuryazarlığının, öğrenciye bilgiye nasıl ulaşacağı konusunda yardımcı olması nedeniyle, bu okuryazarlık türünün derslerinde yoğun bir şekilde kullanıldığını söylemek mümkündür.

- "Daha çok görsel okuryazarliktır. Başむurduğum kaynak kitap ya da internette görseller olabilir. Öğrencileri kitap okumaya yönlendirmeye çalışıyorum. Ancak başarnl olamiyorum." (2K)

- Görsel okuryazarlik. Çünkü insan hafizasinda daha fazla yer ettiğini düşünüyorum.(4E) 
- "Bilgi okuryazarlı̆̆ı. Çünkü öğrencilerden araştırma yapmasmn istiyorum çoğunlukla. Ayn zamanda araştırma yaparken nelere dikkat etmeleri gerektiğini vurguluyorum. Bilgiyle veri arasindaki farkı vurguluyorum. Ama medya okuryazarlğ̆ı ile ilgili de örnekler kullanıyorum."(5K)

Tablo 9. Bilgi Okuryazarlı̆̆ı

\begin{tabular}{ll}
\hline Güvenilir bilgi & $1 \mathrm{~K}, 5 \mathrm{~K}, 7 \mathrm{E}, 8 \mathrm{~K}$ \\
\hline Bilgi kaynakları & $2 \mathrm{~K}, 3 \mathrm{E}, 6 \mathrm{E}, 7 \mathrm{E}, 8 \mathrm{~K}$ \\
\hline Bilgiye nasıl ulaşılacağını bilme & $1 \mathrm{~K}, 2 \mathrm{~K}, 3 \mathrm{E}, 5 \mathrm{~K}, 6 \mathrm{E}, 7 \mathrm{E}$ \\
\hline Anahtar kelimeler & $3 \mathrm{E}$ \\
\hline İnterneti nerede ve nasıl kullanabileceğinin farkında olma & $4 \mathrm{E}$ \\
\hline Yanlış bilgileri ayıklama & $7 \mathrm{E}$ \\
\hline Bilgiyi aktif kullanma & $8 \mathrm{~K}$ \\
\hline Bilginin problemlerin çözümünde kullanılması & $8 \mathrm{~K}$ \\
\hline
\end{tabular}

Bilgi okuryazarı olan bireyin güvenilir bilgiye ulaşabileceğini dört katılımcı düşünmektedir. Katılımcların çoğunluğu, bilgi okuryazarı olan bireyin bilgiye nasıl ulaşılacağını bildiğini düşünmektedir. Ayrıca bilgi kaynakları konusunda da bilgilerinin olduklarını düşünmektedir.

- "Bilgi okuryazarlı̆̆̆ çocuğun bilgiye nasıl doğru bir şekilde ulaşacağını ve bu bilgiyi nasıl elde edebileceğini öğretir. Ve yanlış bilgileri ayıklayabilmeyi ögretir." (7E)

- "Bilimsel bilgilere ulaşma yollarmm bilmek, bunları aktif olarak kullanmak ya da güvenilir kaynaklara nasıl ulaşılacağın bulmak da diyebiliriz. Ya da her türlü bilgiyi doğrudur demeden sorgulamak aynı zamanda. Bazı ögrencilerimiz bunu yapıyor. İnternetten ne bulduysa yazıyor. Kaynağııı sorgulamadan ya da oradaki bilgi doğru mu değil mi sorgulamadan. Derslerimizde bunu öğretmeye çalışıyoruz. Doğru bilgiye ulaştı̆̆ını bilmek kadar elde edilen bilginin problemlerin çözümünde kullanılması. Faydacılık yönünün sorgulanması gerektiğini düşünüyorum. Bu bilgi önemli mi, hangi açıdan önemli, gerekli gibi." (8K) 
Tablo 10. Bilgi okuryazarlığı ve toplumsal yaşama katkısı

\begin{tabular}{ll}
\hline Toplumsal olaylarda kullanma & $1 \mathrm{~K}, 7 \mathrm{E}$ \\
\hline Problemlerini çözme & $2 \mathrm{~K}, 8 \mathrm{~K}$ \\
\hline Haklarını bilme & $2 \mathrm{~K}, 5 \mathrm{~K}$ \\
\hline Bildiklerini paylaşma, yol gösterme, rehberlik etme & $2 \mathrm{~K}, 4 \mathrm{E}, 8 \mathrm{~K}$ \\
\hline Bilgilerini paylaşamama & $3 \mathrm{E}, 6 \mathrm{E}$ \\
\hline Bilgi üretme & $4 \mathrm{E}$ \\
\hline Sorumluluk bilinci & $5 \mathrm{~K}$ \\
\hline Sanatsal etkinliklere katılım & $5 \mathrm{~K}$ \\
\hline Sivil toplum örgütlerinde çalışma & $5 \mathrm{~K}$ \\
\hline Medya bilinci & $7 \mathrm{E}$ \\
\hline Kişinin karakterine hizmet etme & $8 \mathrm{~K}$ \\
\hline
\end{tabular}

Bilgi okuryazarı olan birey katılımcıların çoğunluğuna göre bildiklerini paylaşmakta, yol gösterici bir rehber olma niteliğini taşımaktadır. Toplumsal olaylara aktif olarak katılır. Problemleri çözer, hakları konusunda bilgi sahibidir. Katılımcılar bilgi okuryazarlarının sanatsal etkinliklere katıldıklarını, sivil toplum örgütlerinde çalıştıklarını düşünmektedir. İki katılımc her bilgi okuryazarı olan kişinin bilgisini diğer insanlarla paylaşamayabileceği görüşündedir. Ayrıca bir katılımcı bilgi okuryazarlığının en başta kişinin kendi karakterine hizmet ettiğini düşünmektedir.

- "Daha bilinçli kalır. Haklarm bilir, haklarm arar. Problemlerini çözer. Problem çözebilecek bilgiye sahip. Bildiklerini paylaşır, yol gösterir, rehberlik eder." $(2 \mathrm{~K})$

- "Sosyal hayatında, iş hayatında, öğrenim hayatında karşısına çıkan alternatiflerden hangisinin doğru olduğunu hangisinin yanlış olduğunu fark edebilir ve medyanın ve benzeri sosyal ağlarm kendisini yönlendirmesine izin vermez, hazır bilgi almaktan kaçınr. Bilgiye kendisi ulaşmaya çalısır ve bu neticeleri sonrasinda da kendi özgür iradesiyle bir sonuca bir karara ulaşır ve edindiği bilgileri o şekilde yorumlayarak hem kendine hem topluma katkısı olur."(7E)

- "Toplumdaki kişileri problemlerin çözümünde, bireylerin karşılaştığı, problemin çözümüne yol gösterebilir. Ya kendisi araştırır. Doğru bilgiler nedir? Bu yönde kararlar alnmasina yönlendirebilir. Sadece kendinin araştırması değil, çevresindeki kişilere de doğru kaynakları nasıl ulaşılabileceğini gösterebilir. Bazen şu şekilde de olabilir: Bilgi kaynağı 
kişiler de olabilir. Onların iletişim bilgilerine ulaşılması yönünden ona yardımcı olabilir. Yol ve yöntemleri gösterebilir."(8K)

Tablo 11. Derslerde Kullanılması Gereken Okuryazarlık Türleri

\begin{tabular}{ll}
\hline Ayrı bir derse gerek yok & $1 \mathrm{~K}, 8 \mathrm{E}$ \\
\hline Medya okuryazarlığ1 & $2 \mathrm{~K}$ \\
\hline Alana yönelik görsel okuryazarlık & $3 \mathrm{E}, 4 \mathrm{E}$ \\
\hline Bütün okuryazarlık türlerinin tek bir derste anlatılması & $5 \mathrm{~K}, 7 \mathrm{E}$ \\
\hline Bilgi okuryazarlığ1 & $8 \mathrm{~K}$ \\
\hline
\end{tabular}

Katılımclar "Size göre bölümünüzde alan dersleri dışında görsel okuryazarlık, medya okuryazarlığı ya da bilgi okuryazarlığı dersi verilmeli midir?" sorusuna iki katılımcı ayrı bir derse gerek yok şeklinde cevap vermişlerdir. Katılımcılardan altısı ise okuryazarlık türleriyle ilgili derslerin olması gerektiğine dikkat çekmişlerdir.

- "Bence bu üç kavram birleştirilerek farklı okuryazarlık türleri olarak tek bir ders içinde on dört haftalik sürede verilebilir. Haftalik iki saat olacak şekilde. Tek tek verilmesi mümkün değil."(5K)

- "Medya okuryazarlı̆̆ seçmeli olarak var. Bilgi okuryazarlı̆̆ ayrica olmalı. Çünkü derslerimizde bunun ekstra kullanabiliriz diye bakılıyor. Ama öğrencilerimiz lise mantı̆̆ın sürdürme düşüncesinde olabiliyor. KPSS sınavinda çıkacak sorular yönünden kendilerini geliştirme peşindeler. Araştırmacı olma yönü çok tercih edilmiyor. Onlara bakıldığında araştırmacı değil de sınav odakl çalışma eğilimi daha yüksek. Benim derslerim 4'lerde olduğu zaman araştırmaya harcayacağımı zamanı kayıp olarak görüyor."(8K)

- "Kesinlikle verilmelidir. Çağının gereklerini yeni nesle daha doğru aktarmak ve görsel okuryazarlik algısın doğru bir şekilde yeni nesle anlatmak aydın akademisyenlerin en temel görevidir." (4E)

\section{Sonuç}

Yapılan görüşmeler sonucu katılımcıların okuryazarlık algılarındaki değişimde sosyal medyanın, elektronik kitap okumadaki artışın ve okuryazarlık türlerinin derslerde kullanılmasının etkisi olduğu görülmüştür. 
Dersler için akademisyenlerin çoğu görsel okuryazarlıkla ilgili çalışma yapmaktadır.

Facebook uygulaması başta olmak üzere Twitter, Pinterest gibi sosyal ağların arkadaşlarla iletişim kurmaya yardımcı olması, bilgi alma ve haberleri takip etme gibi nedenlerden dolayı katılımcılar tarafından kullanıldığı görülmüştür. Researchgate ise pek çok katılımcı tarafından bilimsel araştırmaların paylaşılması yönünde kullanılmaktadır.

Dijital okumanın, katılımcıların çoğu tarafından kullanıldığı tespit edilmiştir.

Akademisyenlerin derslerinde en çok bilgi okuryazarlığını ve görsel okuryazarlığı kullandıkları görülmüştür. Medya okuryazarlığı, teknoloji okuryazarlı̆̆ı ve geleneksel okuryazarlıktan daha az yararlanmaktalar. Bu durumun nedenleri arasında görsellerin derse ilgiyi arttırmaya katkı sağlaması, bilgi okuryazarlı̆̆ının öğrenciye bilgiye nasıl ulaşacağı konusunda yardımcı olması yer almaktadır.

Katılımcıların çoğunluğu bilgi kaynakları konusunda da bilgilerinin olduğunu ve bilgi okuryazarı olan bireyin bilgiye nasıl ulaşılacağını bildiğini düşünmektedir.

Bilgi okuryazarı olan birey katılımcıların çoğuna göre bildiklerini paylaşır, yol gösterici bir rehber olma niteliğini taşır. Toplumsal olaylara aktif olarak katılır. Problemleri çözer, hakları konusunda bilgi sahibidir. Ayrıca sanatsal etkinliklere katılır ve sivil toplum örgütlerinde de çalışır.

Katılımcıların çoğu kendi bölümlerinde alan dersleri dışında görsel okuryazarlık, medya okuryazarlığı ya da bilgi okuryazarlığı gibi derslerin olması gerektiğine dikkat çekmişlerdir.

Elde edilen veriler doğrultusunda şu öneriler getirilmiştir:

1. Görsel okuryazarlık, medya okuryazarlığı ve bilgi okuryazarlığ gibi dersler üniversitelerin öğretim programlarına dahil edilebilir.

2. Öğrencilerin bilgiyi elde etmede en çok başvurduğu kaynaklardan biri de medyadır. Bu nedenle medya okuryazarlığı ile ilgili daha kapsamlı çalışmalar yapılabilir. 


\section{EXTENDED ABSTRACT}

\section{Changes in Academicians' Perception of Literacy \\ * \\ Yasemin Uzun - Gamze Çelik
Çanakkale Onsekiz Mart University}

The concept of literacy was initially defined as reading and writing skills. The content of the concept has changed with the development of technology, needs of society and the using of multimedia. Literacy is generally being good at reading, writing, speaking and listening; communicating effectively with others and understanding written information. In the twenty-first century, the concept of literacy includes using of technology, problem-solving, collaboration, and the skills necessary to present information. Literacy is process-oriented and requires lifelong continuity. Information literacy, media literacy, digital literacy, visual literacy, environmental literacy, political literacy and cultural literacy are the most common types of literacy.

The aim of this study is to determine the changes in the perceptions of academics and whether they use literacy types in their courses. For this purpose, 4 male and 4 female academicians working in Çanakkale Onsekiz Mart University Faculty of Education were interviewed in 2018-2019. The academics participating in the research consist of 8 people working at Çanakkale Onsekiz Mart University. 4 of the participants are men, and 4 of them are women. The sample was chosen randomly. One-on-one interviews were held with teachers from different fields such as physics education, PCG, chemistry education, geography education, primary education, history education, Turkish education, education management. Participants are between 25-50 years old.

The interviews were completed with the interview form. Researchers made the interview with some participants and noted what the participants said. Researchers have identified codes from the ideas that emerged during the interviews. Other researchers were interviewed to determine the reliability of these codes. The findings obtained by both researchers were calculated by comparing them with the reliability formula put forward by Miles and Huberman (1994, p.64): 
Reliability $=$ Consensus $/($ Consensus + Disagreement $)=123 /(123+6)=$ 0.95 . As a result of the analyzes, the reliability of the research was found to be .95 . According to Miles and Huberman (1994), for a study to be considered reliable, coding reliability should be at least .80 compatibility level (cited in Creswell, 2013).

In this study, where qualitative method was used, it was found that the perceptions of academicians changed over time.

Findings obtained according to literacy types are given as follows:

When the answers to the question "What kind of changes did you observe in your perception of literacy with developing technology?" asked the participants are examined, 3 participants stated that they could not define the change in their literacy perception. While 3 participants thought that the perception of literacy has changed, 2 participants stated that there is no change in the perception of literacy. There are 2 participants who think that social media has an impact on this change of perception. 1 participant's opinion is that the widespread use of this situation in the course has an impact. 2 participants think that the increase in reading electronic books has an impact.

In the lessons, 5 academics stated that they are working on visual literacy. 2 academicians stated that they could work partly. 1 academician stated that he did not work. 1 participant drew attention to the need for students to gain awareness of reading. Another participant told that the studies carried out in this way are not ethical.

It is seen that the majority of the participants use social networks and most of the time was spent on facebook. However, Pinterest is another social network of interest.

Among the reasons for using social networks, it is seen that especially Facebook has a great effect to communicate with friends. The participants also stated that they use Twitter to get information and follow the news. There are also participants who follow Pinterest with interest.

There are also participants who freeze their social media accounts or prefer not to open them at all. It is seen that there are people who do not use Facebook with the notions that people should not be sincere and that private life should be kept secret. Researchgate is beneficial for many participants in sharing scientific research. However, some participants stated that 
the foreign language creates a problem here. There are also participants who think that ethical problems may arise.

There are two people who prefer to read digital. Three participants prefer to read from printed books. Others read both digital books and printed books.

It is seen that the academics participating in our research mostly use information literacy and visual literacy in their lessons. Media literacy, technology literacy and traditional literacy are less beneficial literacy. This situation can be interpreted as the fact that the visuals contributed to increase the interest in the lesson. It is also possible to say that this type of literacy is used extensively in lessons, since information literacy helps the student to get access information.

Four participants think that an individual who is an information literate can access reliable information. The majority of the participants think that an individual who is an information literate knows how to access information. He also believes that they have knowledge about information sources.

The individual who is an information literate shares what he / she knows according to the majority of the participants. He actively participates in social events. He solves problems and has knowledge about his rights. The participants think that information literate people participate in artistic activities and work in non-governmental organizations. The two participants are of the opinion that each person who is a literate person may not be able to share his knowledge with other people. In addition, a participant thinks that information literacy primarily serves one's own character.

Participants answered the question "Are visual literacy, media literacy or information literacy courses required in your department apart from the field courses?", six of the participants pointed out that there should be lessons on literacy types.

In line with the data obtained, the following suggestions were made:

1. Courses such as visual literacy, media literacy and information literacy can be included in the curriculum of universities.

2. The media is one of the sources that students use most in obtaining information. For this reason, more comprehensive studies can be done on media literacy. 


\section{Kaynakça / References}

Altun, A. (2005). Gelişen teknolojiler ve yeni okuryazarliklar. Ankara: Anı Yayınları.

Aşıcı, M. (2009). Kişisel ve sosyal bir değer olarak okuryazarlık. Değerler Ĕgitimi Dergisi, 7(17), 9-26.

Aytaş, G. ve Kaplan, K. (2017). Medya okuryazarlığı bağlamında yeni okuryazarlıklar. Ahi Evran Üniversitesi Kırşehir Eğitim Fakültesi Dergisi, 18(2), 291-310.

Creswell, J. W. (2013). Nitel, nicel ve karma yöntem yaklaşımları/ araştırma deseni (S. Beşir Demir, Çev.). Ankara: Eğiten Kitap.

Fettahlığlu, P. (2018). Algılanan çevresel sorunların çevre okuryazarlık düzeyine göre analizi. Mersin Üniversitesi Ĕ̆itim Fakültesi Dergisi, 14(1), 404-425.

Fransman, J. (2005). Understanding literacy: A concept paper. EFA Global Monitoring Report.

Güneş, F. (1997). Okuma-yazma öğretimi ve beyin teknolojisi. Ankara: Ocak Yayınları.

Kurbanoğlu, S. S. (2010). Bilgi okuryazarlığı: Kavramsal bir analiz. Türk Kütüphaneciliği, 24(4), 723-747.

Kuş, Z. (2013). Politik okuryazarlık ve aktif vatandaşlık. (E. Gençtürk and K. Karatekin Der.), Sosyal bilgiler için çoklu okuryazarlıklar. Ankara: Pegem Akademi.

Miles, M. B. and Huberman, M. A. (1994). An expanded source book qualitative data analysis. London: Sage Publication.

Ocak, G., ve Karakuş, G. (2018). Öğretmen adaylarının dijital okur-yazarlık öz-yeterliliği ölçek geliştirme çalışması. Kastamonu Education Journal. 26(5), 1427-1436.

Patton, M. Q. (2014). Nitel araştırma ve değerlendirme yöntemleri. Ankara: Pegem Akademi.

Pettersson, R. (1993). Visual information. New Jersey: Educational Technology Publications Englewood Cliffs.

Snyder, I. (2001). A new communication order: researching literacy practices in the network society. Language and Education ,15 (2-3), 117-131.

Tanrıverdi, B., ve Apak, Ö. (2013). Görsel okuryazarlık üzerine bir içerik analizi. Uludă̆ Üniversitesi Eğitim Fakültesi Dergisi, 26(1), 267-293. 
UNESCO (2005). Education for all: Literacy for life; EFA global monitoring report. https://unesdoc.unesco.org/ark:/48223/pf0000141639_xx.xx.xxxx tarihinde adresinden erişilmiştir.

Yılmaz, B. (1989). Okuryazarlık ve okuma alışkanlı̆̆ı üzerine. Türk Kütüphaneciliği, 3(1), 48-53.

\section{Kaynakça Bilgisi / Citation Information}

Uzun, Y. ve Çelik, G. (2020). Akademisyenlerin okuryazarlık algısındaki değişimler. OPUS-Uluslararası Toplum Araştırmaları Dergisi, 15(22), 1134-1156. DOI: 10.26466/opus.646592 